\title{
Primary Bowel Malignant Melanoma with Ileo-Ileal Intussusception
}

\author{
DOREL FIRESCU ${ }^{2}$, CRISTINA SERBAN²*, ANCA NEAGU ${ }^{1}$, DANIELA MIHALACHE ${ }^{1}$, LAURA REBEGEA ${ }^{3}$ \\ 'Dunarea de Jos University of Galati, Faculty of Medicine and Pharmacy, Morphological and Functional Sciences Department, \\ 47 Domneasca Str., 800008, Galati, Romania \\ 2Dunarea de Jos University of Galati, Faculty of Medicine and Pharmacy, Surgical Clinical Department, 47 Domneasca Str., \\ 800008, Galati, Romania \\ ${ }^{3}$ Department of Radiotherapy, Sf. Ap. Andrei Emergency Clinical Hospital, 177 Brailei Str., 800578, Galati, Romania
}

\begin{abstract}
Primary malignantmelanoma of the small bowel is extremely rare. A limited number of cases was described in the specialty literature. The small bowel is most frequently affected by metastatic tumors of other primary lesions, especially epidermal. We report the case of a 77 years old male patient with primary bowel malignantmelanoma, diagnosed histologically and immunohistochemically after segmental ileal resection. It was not discovered a primary lesion atskin, eye, anus and rectum levelor with other localization, through the investigations performed after surgery.
\end{abstract}

Key words: malignant melanoma, intussusception, small bowel

Small bowel malignantmelanoma is rare and represents 1 - $3 \%$ of all malignant tumors of gastrointestinal duct (1). Most of these tumors are secondary lesions of a primary localization of the skin, anus, rectum or eye (2).

The symptomatology is usually unspecific and can vary from abdominal pains $(17-64 \%)$, occult hemorrhages (24 - $84 \%$ ) and weight loss (10 - 57\%) [3]. The diagnostic is usually late, in the complication stage, when the disease becomes an emergency, like intestinal hemorrhage, obstruction and perforation [4].

No matter its primary or secondary character, bowel melanoma remains aggressive, with unsatisfactory prognostic, as compared to other situses. The average global survival is from 4 up to 6 months, with a survival rate smaller than $10 \%$ in 5 years $[5,6]$.

\section{Experimental part}

Material and method

A 77 years old patient from urban environment is admitted to Surgery Clinic II, Sf. Ap. Andrei Emergency Clinical Hospital, Galati, for diffuse abdominal pains, melena, slow bowel movement for feces and gases, weight loss, marked physical asthenia, which had started insidiously 1 month ago. At the admission to hospital, the laboratory explorations had observed the following pathological modifications: WBC $14890 / \mathrm{mmc}, \mathrm{Hb} 8.9 \mathrm{~g} /$ $\mathrm{dL}$, Ht $28.10 \%$, PLT 723000/mmc, urea $41 \mathrm{mg} / \mathrm{dL}$.Plain abdominal radiography without changes; the abdominal ultrasound highlighted intestinal loop with reduced peristaltic. Superior and inferior digestive endoscopy did not find the existence of a tumor formation, the tumor markers being in normal limits. After a preliminary hematic rebalancing, it was decided to perform exploratory laparotomy, during which jejunal and ileal disseminated tumors, entero-enteral intussusception had been observed. Minimum segmental enterectomy, desintussusception was performed for biopsy. His evolution after surgery was favorable, the patient being released from hospital after 12 days from the surgery. The conventional histopathological exam in the standard coloration, hematoxylin-eosin (H\&E), was performed in 6 blocks included in paraffin, which included fragments of small bowel, presenting at submucous level, with mucosa muscular compliance, focally with protrusion in the lamina propria, with mucosal ulceration, a malignant tumor proliferation with architecture under the form of compact strands and marginal nests composed of epithelioid cells with moderate and focally marked nuclear pleomorphism, frequent mitotic figures and frequent apoptosis, with moderate inflamed peritumoral lymphocytic infiltrate, with area-associated macrophages, some pigmented (melanophages). Intravascular-lymphocytic tumor emboli (LV1) was detected and perineural invasion ( $\mathrm{PnO}$ ) was not detected.

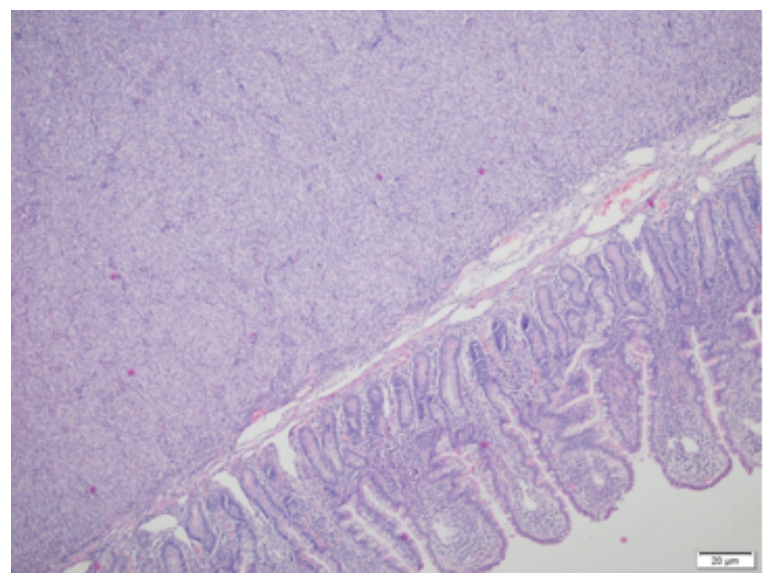

Fig. 1.Malignant melanoma at intestinal submucosa level, without invasion of mucosa musculature and mucosa, $H \& E$, objective $4 X$

The immunohistochemical complementary tests (IHC) revealed the following: melanocytic markers HMB45, Melan A, MITF, S100 had positive, diffuse reactions in tumor proliferation; the Ki67 proliferation index was positive in about $95 \%$ of the tumor cells, indicating intense mitotic activity, CK8 / 18 - absent reaction in tumor proliferation, positive in the intestinal epithelium excluding adenocarcinoma diagnosis, CD45 - absent reaction in tumorcells, positive in intra- and peritumoral lymphocytes, excluding lymphoma diagnosis, C-KIT - membrane reaction with low and moderate intensity in about $30 \%$ of 


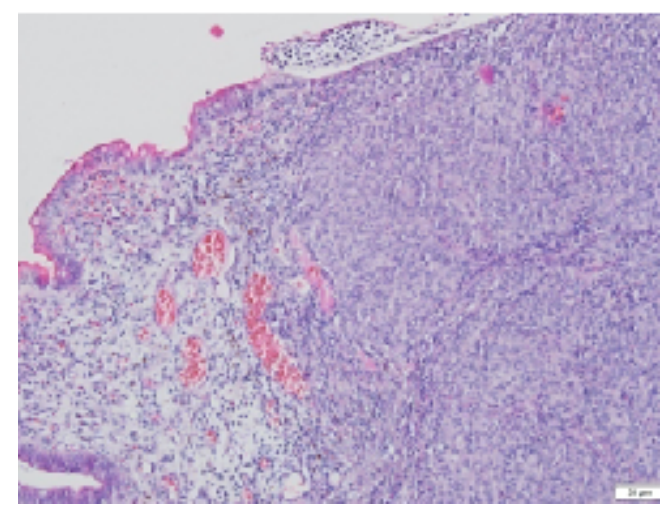

Fig. 2.Tumor invasion at laminapropria level, with ulceration of the mucosa, H\&E, ob. 10X

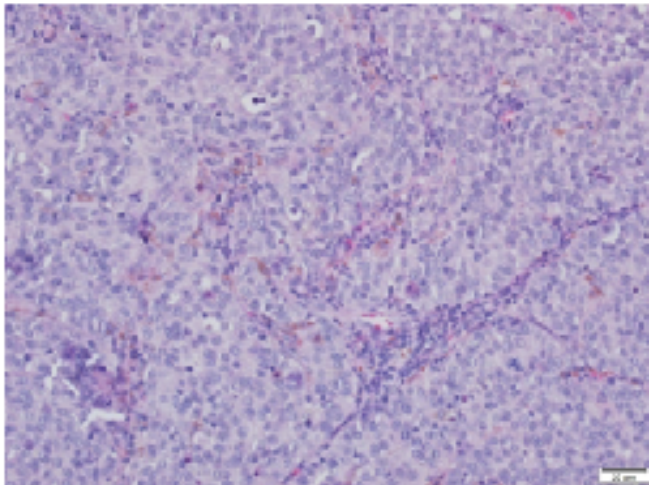

Fig. 3.Compact ranges of epithelioid tumor cells, with moderate nuclear pleomorphism, with mitotic figures, lymphocyticperitumoralinfiltrate, $H \& E$, ob. 20X

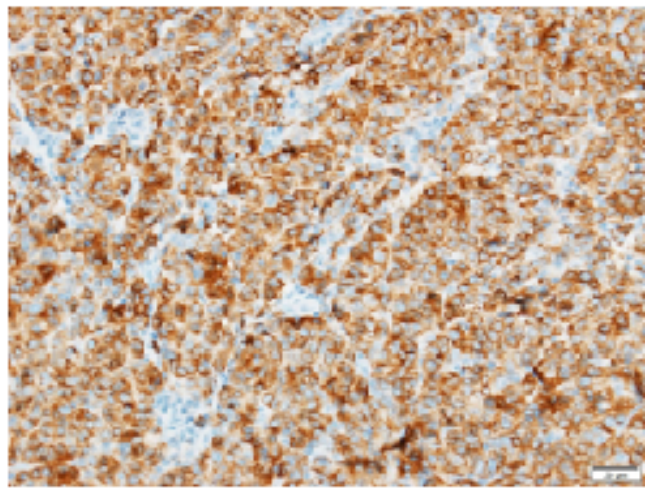

Fig. 4. HMB45 - strong membrane marking, diffuse in tumor proliferation, ob. 20X

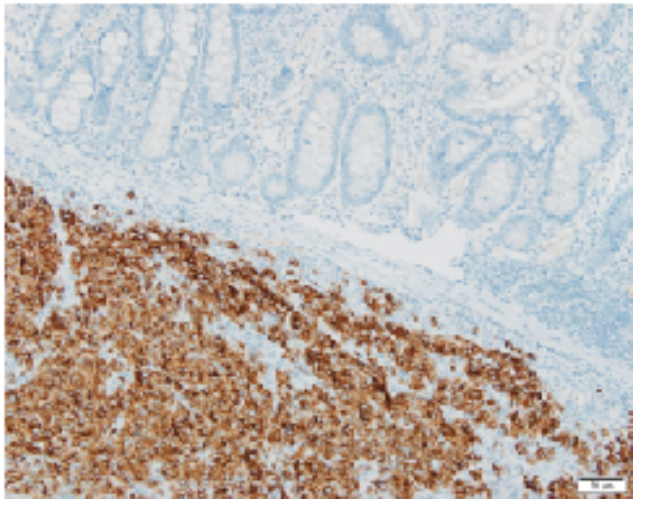

Fig. 5. Melan A -intense positivecytoplasmatic marking, diffuse in tumor proliferation, negative in intestinal mucosa, ob. 10X

tumor cells, excluding gastrointestinal stromal tumor diagnosis.

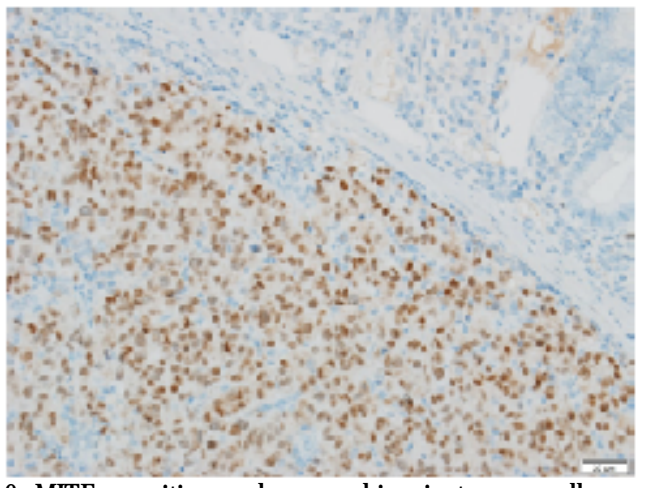

Fig. 6. MITF -positivenuclear marking in tumor cells, negative in intestinal mucosa, ob. 20X

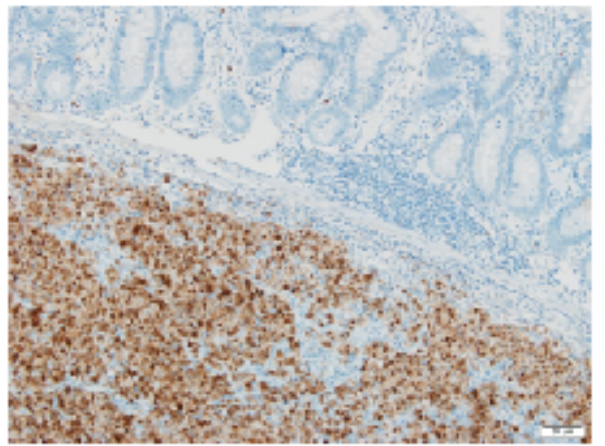

Fig. 7. S100 -positive nuclear andcytoplasmatic marking in most of tumor cells, negative in intestinal mucosa, ob. 10X

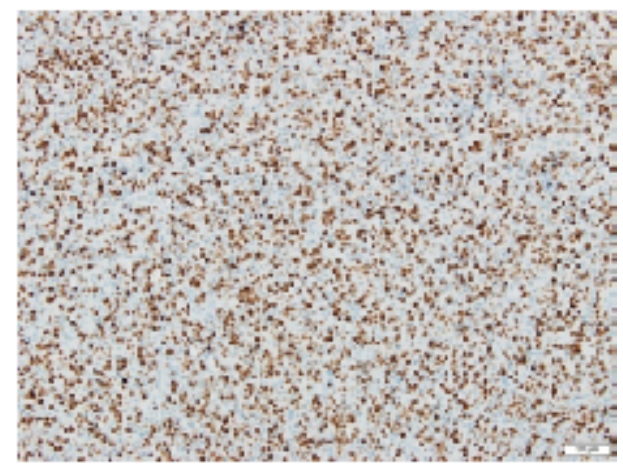

Fig. 8. Ki67 - positive nuclear marking in around $95 \%$ of tumor cells, negative in intestinal mucosa, ob.10X

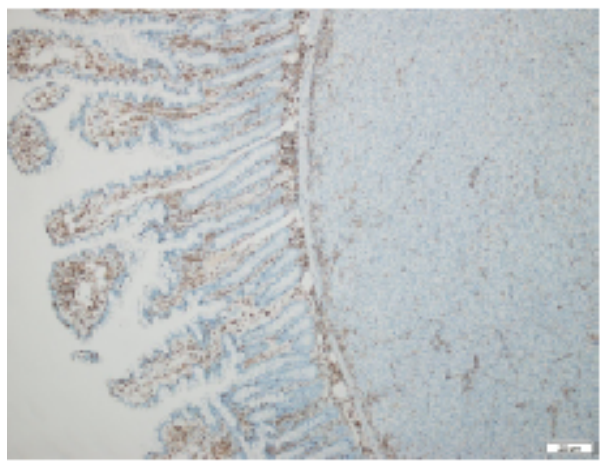

Fig. 9. CD45 - negative in tumor cells, positive in peritumoral lymphocytes and in the lymphocytes from lamina propria, ob. $4 X$

Thus, histopathological diagnosis was established: multiple intestinal malignant melanoma determinations with epithelioid cellularity, with present lymphatic invasion (LV1) with HMB45 +, Melan A +, S100 +, MITF + immunophenotype. 


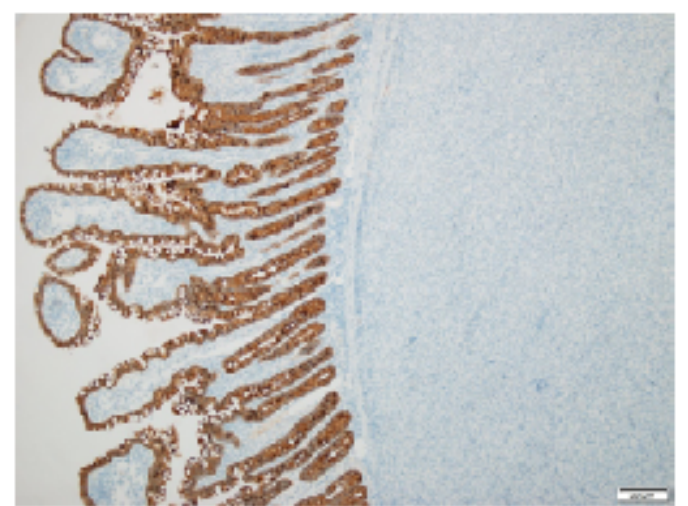

Fig. 10. CK 8-18 -negative marking in tumor proliferation, positive in epithelial cells of the mucosa, ob. 4X

\section{Results and discussions}

Normally, the small bowel and the colon do not contain melanocytes. Embryonically, they appear from the neuronal melanoblasts that migrate to distal ileum through the umbilical-mesenteric tract $[7,8]$. They differentiate by Amine Precursor Uptake and Decarboxylase (APUD), and may undergo neoplastic transformation in non-cutaneous situses [9]. According to this theory, the ileum is the most common situs for the development of primary melanoma of the small bowel, although some authors still deny the primary existence of melanoma in the gastrointestinal tract.

Some researchers believe that all melanomas of the $\mathrm{Gl}$ tract would be metastatic in origin[2,10,11]. This opinion is based on the fact that some epidermal melanomas can regress spontaneously $[9,12]$.

Before diagnosing malignant melanoma of the small bowel, it is important to exclude other primary melanomas in other situses. The criteria for the diagnosis of primary melanoma include: the absence of other melanomas in primary situses and without history of atypical melanocytic lesions at skin, retina, anal tract level and occasionally at penis, esophagus or vagina level $[1,2]$.

In order to determine if malignant melanoma of the small bowel is a primary lesion, Sacks et al. [13] established three diagnostic criteria: i) single lesion, ii) other organs without primary lesions and absence of lymph ganglion enlargement, and iii) survival time over one year after diagnosis. [14]. In another study, Blecker and et al.[15] proposes the following criteria for the diagnosis of primary intestinal melanoma of the small bowel: i) the presence of a solitary mucosal lesion in the intestinal epithelium ii) the absence of melanoma or atypical skin melanocytic lesions and iii) the presence of intramuscular melanoma lesions in the upper or adjacent intestinal epithelium.

Histological criteria for highlighting the primary melanoma are the proliferation of atypical junctional melanocytes and atypical melanocytic cells in the basal layer of the surface epithelium. Other indications of primary lesions are the presence of peritumoral lymphocyte infiltration $[3,16]$.

24 cases of primary malignant melanoma $[1,2,6$, 1735] have been reported in the specialty literature, according to the criteria proposed by Sacks et al. All cases described in the literature present a broad age range of patients, with the highest prevalence in those over 40 years of age.

\section{Conclusions}

Primary malignant melanomas of the small bowel are extremely rare neoplasms. They are solitary, endoluminalmasses with aggressive clinical progression

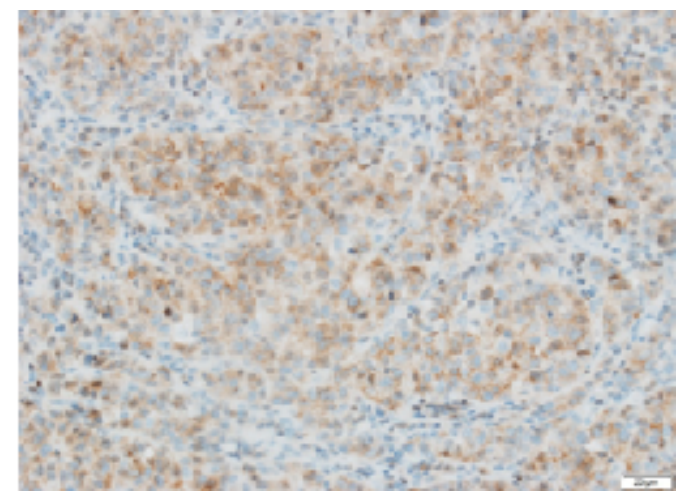

Fig. 11.C-KIT - membrane reaction of low and moderate intensity in about $30 \%$ of tumor cells, ob. $20 \mathrm{X}$

and poor prognosis. Surgical resection is essential to improve the prognostic.

\section{References}

1. ATMATZIDIS KS, PAVLIDIS TE, PAPAZIOGAS BT, PAPAZIOGAS TB.

Primarymalignant melanoma of the small intestine: report of a case.Surg Today. 2002;32(9):831-3.

2. KRUGER S, NOACK F, BLÖCHLE C, FELLER AC. Primary malignant melanomaof the small bowel: a case report and review of the literature.Tumori. $2005 \mathrm{~J}$ an-Feb;91(1):73-6.

3. TIMMERS TK, SCHADD EM, MONKELBAAN JF, MEIJ V. Survival afterResection of a Primary Malignant Melanoma of the Small Intestinein a Young Patient: Report of a Case. Case Rep Gastroenterol.2013 May-Aug; 7(2):251-260.

4. SCHUCHTER LM, GREEN R, FRAKER D. Primary and metastatic diseasesin malignant melanoma of the gastrointestinal tract. Curr OpinOncol. 2000;12:181-185.

5. POGGI SH, MADISON JF, HWU WJ, BAYAR S, SALEM RR. Colonicmelanoma, primary or regressed primary.J ClinGastroenterol. 2000;30:441-444.

6. MITTAL VK, BODZIN JH. Primary malignant tumors of the small bowel. Am J Surg. 1980 Sep;140(3):396-9

7.PATTI R, CACCIATORI M, GUERCIO G, TERRITO V, DI VITA G. Intestinal melanoma: A broad spectrum of clinical presentation. IJS Case Reports 2012; 3(8):395-398.

8. RADHA S, AFROZ T, RATNAKAR C, REDDY AK, SATYANARAYANA G. Small bowel metastasis of malignant melanoma. Indian J Surg2006; 68:222-223.

9. CHANG AE, KARNELL LH, MENCK HR. The National Cancer Data Base report on cutaneous and noncutaneous melanoma: a summary of 84,836 cases from the past decade. The American College of Surgeons Commission on Cancer and the American Cancer Society.Cancer. 1998;83:1664-78

10.SCHUCHTER LM, GREEN R, FRAKER D. Primary and metastatic diseases in malignant melanoma of the gastrointestinal tract. CurrOpinOncol. 2000;12:181-5.

11. WILSON BG, Anderson JR. Malignant melanoma involving the small bowel. Postgrad Med J. 1986;62:355-357.

12. ELSAYED AM, MOTAZ A, UGOCHUKWU CN, SOBIN LH. Malignant melanomas in the small intestine: a study of 103 patients. Am J Gastroenterol. 1996;91:1001-1006.

13. SACKS DL, LOWE L, CHANG AE, et al. Do primary small intestinalmelanomas exist? Report of a case. Jam Acad Dermatol.1999;41:1042-1044.

14.GANG LI, XIAO JIANG TANG, et al. Intestinal obstruction due to primary intestinal melanoma in patient with a history of rectal cancer resectioning: A case report. MolClinOncol. Mar 2014;2(2):233-236. 15.BLECKER D, ABRAHAM S, FURTH EE, KOCHMAN ML. Melanoma in the gastrointestinal tract. Am J Gastroenterol. 1999;94:3427-3433 
16.ELSAYED AM, ALBAHRA M, NZEAKO UC, SOBIN LH. Malignant melanomas in the small intestine: a study of 103 patients. Am J Gastroenterol. 1996;91:1001-1006.

17. KADIVAR TF, VANEK VW, KRISHNAN EU. Primary malignant melanoma of the small bow el: a case study. Am Surg. 1992;58:418-422. 18. MANOURASA, GENETZAKISM, LAGOUDIANAKISE, etal. Malignant gastrointestinal melanomas of unknown origin: should it be considered primary? World J Gastroenterol. 2007;13:4027-4029.

19. AMAR A, JOUGON J , EDOUARD A, LABAN P, MARRY JP, HILLION G. Primary malignant melanoma of the small intestine. GastroenterolClin Biol. 1992; 16:365-367

20. KRAUSZ MM, ARIEL I, BEHAR AJ. Primary malignant melanoma of the small intestine and the APUD cell concept.J SurgOncol. 1978;10:283-288.

21. RAYMOND AR, RORAT E, GOLDSTEIN D, LUBAT E, STRUTYNSKY N, GELB A. An unusual case of malignant melanoma of the small intestine. Am J Gastroenterol. 1984;79:689-692.

22. TABAIE HA, CITTA RJ, GALLO L, BIONDI RJ , MEOLI FG, SILVERMAN

$D$. Primary malignant melanoma of the small intestine: report of a case and discussion of the APUD cell concept. J Am Osteopath Assoc. 1984;83:374-377.

23. YASHIGE H, HORISHI M, SUYAMA Y, et al. A primary malignant melanoma of the small intestine.Gan No Rinsho. 1990;36:955-958.

24. RAMADAN E, MITTELMAN M, KYZER S, CHAIMOFF C. Unusual presentation of malignant melanoma of the small intestine. Harefuah.1992;122:634-635.

25. LIZASOAIN UJ, GONZALEZ SAP, DE CASTRO C], et al. Melanoma of the small intestine and adenocarcinoma of the colon. GastroenterolHepatol. 1995;18:323-325
26. WADE TP, GOODWIN MN, COUNTRYMAN DM, JOHNSON FE. Small bowel melanoma: extended survival with surgical management. Eur J SurgOncol. 1995;21:90-91.

27. CHRISTOVA S, MEINHARD K, MIHAILOV I, ALEXIEV B. Three cases of primary malignant melanoma of the alimentary tract. Gen DiagnPathol. 1996;142:63-67.

28. KOGIRE M, YANAGIBASHI K, SHIMOGOU T, et al. Intussusception caused by primary malignant melanoma of the small intestine. Nihon Geka Hokan. 1996;65:54-59.

29. SORENSEN YA, LARSEN LB. Malignant melanoma in the small intestine. UgeskrLaeger. 1998;160:1480-1481.

30. KHOSHROWSHAHI E, HORVATH W. Primary malignant melanoma of the small intestine: a case report. Röntgenpraxis. 2002;54:220-223. 31. YANAR H, COSKUN H, AKSOY S, TEKINEL M. Malignant melanoma of the small bowel as a cause of occult intestinal bleeding: case report. Ulus TravmaDerg. 2003;9:82-84.

32. IIJIMA S, OKA K, SASAKI M, et al. Primary jejunal malignant melanoma first noticed because of the presence of parotid lymph node metastasis. J Am AcadDermatol. 2003;49:319-323.

33. KIM W, BAEK J M, SUH YJ , JEON HM, KIM JA. Ileal malignant melanoma presenting as a mass with aneurysmal dilatation: a case report. J Korean Med Sci. 2004;19:297-301.

34. CRIPPA S, BOVO G, ROMANO F, MUSSI C, UGGERI F. Melanoma metastatic to the gallbladder and small bowel: report of a case and K.G. Spiridakis et al. review of the literature. Melanoma Res. 2004; 14:427-430.

35. GURAYA SY, AL NAAMI M, AL TUWAIJRI T, ARAFAH MM. Malignant melanoma of the small bowel with unknown primary: a case report. J Ayub Med Coll Abbottabad. 2007;19:63-65.

Manuscript received:6.05.2019 